ISSN: 2576-8875

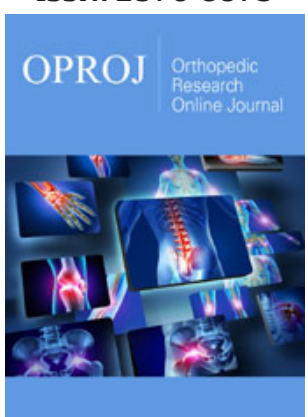

*Corresponding author: Mohammad Sheeba kauser, Phd scholar, Apex university, India

Submission: 每 June 14, 2021

Published: 眥June 18, 2021

Volume 8 - Issue 3

How to cite this article: Maruthy $\mathrm{T}$, Mohammad Sheeba kauser, Himabindu P, Subhasis Karmakar. Effectiveness of Scapular Stabilization Exercises in Preventing Upper Limb Injuries in Overhead Athletes. Ortho Res Online J. 8(3). OPROJ. 000686. 2021.

DOI: 10.31031/OPROJ.2021.08.000686

Copyright@: Mohammad Sheeba kauser This article is distributed under the terms of the Creative Commons Attribution 4.0 International License, which permits unrestricted use and redistribution provided that the original author and source are credited.

\section{Effectiveness of Scapular Stabilization Exercises in Preventing Upper Limb Injuries in Overhead Athletes}

\author{
Maruthy $\mathbf{T}^{1}$, Mohammad Sheeba kauser $^{2 *}$, Himabindu $\mathbf{P}^{1}$ and Subhasis \\ Karmakar ${ }^{3}$ \\ ${ }^{1}$ Chief physiotherapist , India \\ ${ }^{2}$ Phd scholar, Apex university, India \\ ${ }^{3}$ Physiotherapist, UAE
}

\begin{abstract}
A disturbance in scapulothoracic kinematics can cause negative biomechanic effects on the upper extremity function. Alteration in scapular function can be the factor for upper extremity injuries. Purpose of this study was to know the effectiveness of scapular muscle strengthening in overhead athletes in decreasing the incidence of upper extremity injuries. A section of exercises aiming for the activation and strengthening of scapular muscles was included in the daily regime of overhead athletes. Stretching exercises were prescribed to balance the shoulder mobility. Overhead sports included in this study are badminton, handball, volleyball and javelins throw. 94 elite athletes of the Andhra Pradesh state academy were included in this study. Training hours varies for each sport; rate of incidence of upper extremity injuries is calculated per 1000 hours. Incidence of injuries has reduced significantly after inclusion of scapular strengthening program. This data signifies the importance of scapular kinematics and muscle balance in upper extremity function and encourages those caring for overhead athletes to include exercises for restoration of scapular muscle balance as an essential part of athletic training.
\end{abstract}

\section{Introduction}

Overhead athletes are susceptible to upper limb injuries because of the high repetitive forces, poor techniques and dysfunctional adaptations. Scapula and the associated muscles play an important role in the upper extremity function. Effective synchronous co contraction of the scapular muscles provides a stable base of support for the glenohumeral joint to function optimally. Thus, the scapula acts as a funnel for the efficient transfer of force generated in the kinetic chain. Weak or Poor scapular muscle control puts the glenohumeral joint and other components in the kinetic chain at a higher risk for injuries.

Injuries of the rotator cuff, tendinitis and ruptures of biceps, pectoralis major, impingements, epicondylitis are mainly observed. Overuse injuries or repetitive strain injuries are also observed in the upper extremity. Improving the scapulothoracic joint control and muscle balance can help in injury prevention.

The association between altered scapular kinematics and shoulder pathologies has been strongly established several times [1-9]. Abnormal scapular orientations were also observed in athletes with cervical or neck issues clinically in our sports academy. This abnormal scapular kinematics is because of force imbalances, flexibility deficits, and altered recruitment patterns. Bony factors include thoracic kyphosis, clavicular fracture nonunion, and shortened clavicular malunion. Joint-related causes include high-grade AC instability and glenohumeral joint internal derangement. Altered scapular kinematics is also observed in healthy athletes without any history of injuries as an adaptation [10-15]. All together this abnormal kinematics was termed as scapular dyskinesia, scapular dyskinesis and sick scapula by several authors. 


\section{Causes of altered scapular kinematics}

A soft tissue flexibility deficit is one of the factors, because of overtraining particular group of shoulder and scapular muscles. Pectoralis minor which starts from 3-5 ribs and attaches to the coracoid process of scapula can become shortened because of the repetitive throwing movements. This shortened or tight pectoralis minor will tilt the scapula anteriorly and internally rotate (protraction) thus changing the kinematics. Inflexibility and muscle imbalances in other scapular muscles like the levator scapulae, serratus anterior, and trapezius could possibly contribute to the altered scapular kinematics.

Fatigue can also be a factor for altered scapular kinematics. Several studies have found that fatigue in scapular muscles induces scapular dyskinesia or altered scapular kinematics [16-18]. Because of repetitive movements or over training the scapular stabilizers tend to get fatigued and inactive and may not compensate the destabilizing forces produced during overhead athletic actions.

Traditional strength training by the coaches doesn't concentrate on the smaller scapular muscles which play a crucial role in stabilizing the scapula. Our study is to find how much does the scapular stabilization exercises helps in decreasing the incidence of upper limb injuries. An exercise protocol which activates and strengthens the scapular muscles was included in the daily routine of the athletes. Incidences of upper limb Injuries for a period of 20 months before and after are calculated.

Overhead sports included in this study were badminton, volleyball, handball and javelins throw. All the athletes were state level players. Participation time or training time varies for all the disciplines. Incidence was calculated on an average of 1000 hours.

\section{Incidence of upper limb injuries}

In the present study 94 elite athletes of age group between 1318 years were included from Sports academy of Andhra Pradesh state, There were 24 female and 70 male athletes of badminton, handball, volleyball and javelin throwers.

Badminton player's trains for 48 weeks in a year at 20 hours per week, which gives the injury exposure time of $48 \times 20=960$ hours. Each player on an average sustained 6 upper limb injuries. Rate of incidence $=6 / 960 \times 1000=6.25$.

Volleyball players train for 42 weeks in an academic year at 18 hours per week, which gives an injury exposure of $42 \times 18=756$ hours. Each player on an average sustained 4.5 upper extremity injuries. Rate of incidence $=4.5 / 756 \times 1000=5.95$.

Handball players train for 42 weeks in an academic year at 18 hours per week, which gives an injury exposure of $42 \times 18=756$ hours. Each player on an average sustained 7 upper extremity injuries. Rate of incidence $=7 / 756 \times 1000=9.25$.

Javelin throwers train for 37 weeks in an academic year at 15 hours per week, which gives an injury exposure of $37 \times 15=555$ hours. Each player on an average sustained 6 upper limb injuries.
Rate of incidence $=6 / 555 \times 1000=10.8$.

Javelin throwers complained the highest number of upper limb injuries, this can be because of the high intensity forces placed on the shoulder complex when compared to other sports in the study. After including the scapular strengthening program in their routine the average number of injuries sustained were reduced significantly.

\section{Exercise protocol}

This exercise program is emphasized to activate and strengthen the scapular stabilizers. Protocol followed includes strengthening exercises for scapular stabilizers (Deltoid, Rotator cuff muscles, Middle trapezius, Lower trapezius, Serratus anterior and Rhomboids, lattismus dorsi) and stretching for 20-30 sec / 5 times. All these exercises were completed during the warm-up prior to their training for 3 days in a week during in - season and five days in a week during off season (April - July). Two sets for each exercise with 10-15 repetitions in each set and intermittent rest in between. All the coaches and fitness trainers were educated about the exercises in detail.

\section{Exercises}

Closed and open chain kinematic exercises were included in the program. Scapular clock exercises, Wall washes in vertical and diagonal directions for activation and strengthening of rotator cuff exercises. In Scapular clock exercises the hand is placed on a wall or a ball and the arm along with scapula is moved in elevation and depression (the 12 and 6 o'clock positions) and retraction and protraction (the 9 and 3 o'clock positions. This exercise is done in different degrees of abduction and flexion.

Black burn retraction exercises for strengthening the retractor muscles and posterior rotator cuff muscles. Seated pushups for strengthening scapular depressors, lattismus dorsi and teres major muscles. Alternating punches with therabands in diagonal, upward and downward directions, scapular pushups/ push plus and low row exercises. These exercises facilitate serratus anterior muscle activation and strengthening.

For trapezius, three exercises were included. Side lying - external rotation, side lying - forward flexion, prone - horizontal abduction with external rotation, and prone extension. These exercises were found to be the most appropriate for restoring the intramuscular trapezius muscle balance [19].

Multiplanar movements like PNF D2 pattern, lawn mower exercises with therabands and backward throws which mimic the functional movements and conditions the muscles in three planes were included. Medicine ball throws in different directions and varieties like twisting throw, unilateral overhead throw, soccer throw exercises were included.

Stretches included in this program are sleeper stretch and cross body stretch for posterior capsular tightness, corner stretch for pectoralis muscles as these tend to get tightened. Sleepers stretch and cross body stretches have been shown to be effective in restoring the ROM [20-22]. 
Table 1.

\begin{tabular}{|c|c|c|c|c|c|c|}
\hline Sport & $\begin{array}{c}\text { Total Weeks } \\
\text { of Training } \\
\text { in a Year }\end{array}$ & $\begin{array}{c}\text { Hours } \\
\text { Per Week }\end{array}$ & $\begin{array}{c}\text { Injury } \\
\text { Exposure } \\
\text { Time }\end{array}$ & $\begin{array}{c}\text { Average } \\
\text { Injuries in } \\
\text { Upper Limb } \\
\text { Sustained }\end{array}$ & $\begin{array}{c}\text { Average Injuries } \\
\text { Sustained after } \\
\text { Including Scapular } \\
\text { Strengthening } \\
\text { Program } \\
\text { Rate of Incidence }\end{array}$ \\
\hline Badminton & 48 & 20 & $48 \times 20=960$ & 6 & $6 / 960 \times 1000=6.25$ & 2 \\
\hline Volleyball & 42 & 18 & $42 \times 18=756$ & 4.5 & $4.5 / 756 \times 1000=5.95$ & $3 / 756 \times 1000=3.95$ \\
\hline Handball & 42 & 18 & $42 \times 18=756$ & 7 & $7 / 756 \times 1000=9.25$ & $3 / 756 \times 1000=3.95$ \\
\hline Javelin throw & 37 & 15 & $37 \times 15=555$ & 6 & $6 / 555 \times 1000=10.8$ & 3.5 \\
\hline
\end{tabular}

\section{Scientific rationale for scapular stabilization program}

Altered scapular kinematics plays critical roles in the pathologic processes of upper extremity injuries. Abnormal Scapular kinematics results from imbalances of the periscapular muscles secondary to fatigue, direct trauma, poor techniques and poor training methods. It can negatively impact shoulder function in several ways. For instance, for the athletes to reach the extremes of motion, the scapula must rotate counterclockwise (in the sagittal plane) so the acromion elevates to prevent impingement of the soft tissues. The scapula should also retract accordingly to keep the glenoid cavity centered under the humerus for maintaining stability. If the scapula fails in these functions appropriately, there is hyperangulation of the humerus relative to the glenoid and excessive stress on the structures supporting the joint.

Scapula is part of the kinetic chain, transfers energy from legs, hips and trunk to the upper extremity. Destabilization of the scapula results in abnormal kinematics of the upper extremity which leads to injuries in the long run. Several authors have examined the effectiveness of scapula-based rehabilitation programmes [23-30]. In a study by Merolla et al. [27], scapular training has improved glenohumeral muscle function in healthy non injured athletes. De Mey et al. [29] study has found that after 6 weeks of training the scapular muscles has showed improved scapular muscle recruitment in overhead athletes. And also SPADI scores have shown less pain and functional improvement after the scapularbased rehabilitation program. Few Randomized control trials have confirmed that when a scapular based rehabilitation protocols are implemented, outcomes were better regarding function and strength $[23,30]$.

\section{Conclusion}

The normal function of the scapula and scapulothoracic muscles is crucial for the overall function of the upper extremity. Weakness of these muscles alters the biomechanics of the upper extremity with resultant excessive stress and forces imparted to the proximal and distal components in the kinetic chain. Strengthening the scapular muscles has shown better outcomes in rehabilitation of several upper extremity injuries like lateral epicondylalgia [31,32]. Several studies have shown alterations in flexibility, or muscle imbalance are common in patients with shoulder injury. Alterations in kinematics have been documented in shoulder impingement, rotator cuff injury, and instability [33-37]. In the normal kinematics of overhead movements the force generated from the legs and trunk transferred to the upper extremity through the scapula. Thus, scapula acts as stable base, funnel and force regulator in the overhead actions. To fulfill these roles the 17 muscles which has attachment to the scapula has to function synchronously. Poor training methods, overloading, muscle fatigue alters the kinematics leading to injuries.

In our present study strengthening the scapular muscles has significantly decreased the incidence of upper extremity injuries. Apart from these coaches have also reported better performance of the athletes, regarding accuracy.

\section{References}

1. Ludewig PM, Cook TM (2000) Alterations in shoulder kinematics and associated muscle activity in people with symptoms of shoulder impingement. Phys Ther 80(3): 276-291.

2. Laudner KG, Myers JB, Pasquale MR, Bradley JP, Lephart SM (2006) Scapular dysfunction in throwers with pathologic internal impingement. J Orthop Sports Phys Ther 36(7): 485-494.

3. Hébert LJ, Moffet H, McFadyen BJ, Dionne CE (2002) Scapular behavior in shoulder impingement syndrome. Arch Phys Med Rehabil 83(1): 6069.

4. Lin JJ, Hanten WP, Olson SL, Roddey TS, Soto-quijano DA, et al. (2005) Functional activity characteristics of individuals with shoulder dysfunctions. J Electromyogr Kinesiol 15(6): 576-586.

5. McClure PW, Michener LA, Karduna AR (2006) Shoulder function and 3-dimensional scapular kinematics in people with and without shoulder impingement syndrome. Phys Ther 86(8): 1075-1090.

6. Illyés A, Kiss RM (2006) Kinematic and muscle activity characteristics of multidirectional shoulder joint instability during elevation. Knee Surg Sports Traumatol Arthrosc 14(7): 673-685.

7. Ogston JB, Ludewig PM (2007) Differences in 3-dimensional shoulder kinematics between persons with multidirectional instability and asymptomatic controls. Am J Sports Med 35(8): 1361-1370.

8. Warner JJ, Micheli LJ, Arslanian LE, Kennedy J, Kennedy R (1992) Scapulothoracic motion in normal shoulders and shoulders with glenohumeral instability and impingement syndrome. A study using Moiré topographic analysis. Clin Orthop Relat Res (285): 191-199.

9. Kibler WB, Ludewig PM, McClure P, Uhl TL, Sciascia A (2009) Scapular summit 2009: Introduction. July 16, 2009, Lexington, Kentucky. J Orthop Sports Phys Ther 39(11): A1-A13.

10. Oyama S, Myers JB, Wassinger CA, Ricci DR, Lephart SM (2008) Asymmetric resting scapular posture in healthy overhead athletes. J Athl Train 43(6): 565-570. 
11. Myers JB, Laudner KG, Pasquale MR, Bradley JP, Lephart SM (2005) Scapular position and orientation in throwing athletes. Am J Sports Med 33(2): 263-271.

12. Laudner KG, Stanek JM, Meister K (2007) Differences in scapular upward rotation between baseball pitchers and position players. Am J Sports Med 35(12): 2091-2095.

13. Silva RT, Hartmann LG, Laurino CF, Biló JP (2010) Clinical and ultrasonographic correlation between scapular dyskinesia and subacromial space measurement among junior elite tennis players. Br J Sports Med 44(6): 407-410.

14. Cools AM, Johansson FR, Cambier DC, Velde AV, Palmans T, et al. (2010) Descriptive profile of scapulothoracic position, strength and flexibility variables in adolescent elite tennis players. Br J Sports Med 44(9): 678684.

15. Kawasaki T, Yamakawa J, Kaketa T, Kobayashi H, Kaneko K (2012) Does scapular dyskinesis affect top rugby players during a game season? J Shoulder Elbow Surg 21(6): 709-714.

16. Zago M, Kawczyński A, Klich S, Pietraszewski B, Galli M, et al. (2020) Fatigue-induced scapular dyskinesis in healthy overhead athletes. Front Bioeng Biotechnol 21(8): 302.

17. Ebaugh DD, McClure PW, Karduna AR (2005) Effects of shoulder muscle fatigue caused by repetitive overhead activities on scapulothoracic and glenohumeral kinematics. J Electromyogr Kinesiol 16(3): 224-235.

18. Joshi M, Thigpen CA, Bunn K, Karas SG, Padua DA (2011) Shoulder external rotation fatigue and scapular muscle activation and kinematics in overhead athletes. J Athl Train 46(4): 349-357.

19. Cools AM, Dewitte V, Lanszweert F, Notebaert D, Roets A, et al. (2007) Rehabilitation of scapular muscle balance: Which exercises to prescribe? Am J Sports Med 35(10): 1744-1751.

20. Maenhout A, Eessel VV, Dyck VL, Vanraes A, Cools A (2012) Quantifying acromiohumeral distance in overhead athletes with glenohumeral internal rotation loss and the influence of a stretching program. Am J Sports Med 40(9): 2105-2112.

21. Manske RC, Meschke M, Porter A, Smith B, Reiman M (2010) A randomized controlled single-blinded comparison of stretching versus stretching and joint mobilization for posterior shoulder tightness measured by internal rotation motion loss. Sports Health 2(2): 94-100.

22. Cools AM, Johansson FR, Cagnie B, Cambier DC, Witvrouw EE (2012) Stretching the posterior shoulder structures in subjects with internal rotation deficit: Comparison of two stretching techniques. Shoulder \& Elbow 4(1): 56-63.

23. Struyf F, Nijs J, Mollekens S, Jeurissen I, Truijen S, et al. (2013) Scapularfocused treatment in patients with shoulder impingement syndrome: A randomized clinical trial. Clin Rheumatol 32(1): 73-85.

24. Tate AR, McClure PW, Young IA, Salvatori R, Michener LA (2010) Comprehensive impairment-based exercise and manual therapy intervention for patients with subacromial impingement syndrome: A case series. J Orthop Sports Phys Ther 40(8): 474-493.
25. Seitz AL, McClure PW, Finucane S, Ketchum JM, Walsworth MK, et al. (2012) The scapular assistance test results in changes in scapular position and subacromial space but not rotator cuff strength in subacromial impingement. J Orthop Sports Phys Ther 42(5): 400-412.

26. Velde VA, Mey DK, Maenhout A, Calders P, Cools AM (2011) Scapularmuscle performance: Two training programs in adolescent swimmers. J Athl Train 46(2): 160-167.

27. Merolla G, Santis DE, Sperling JW, Campi F, Paladini P, et al. (2010) Infraspinatus strength assessment before and after scapular muscles rehabilitation in professional volleyball players with scapular dyskinesis. J Shoulder Elbow Surg 19(8): 1256-1264.

28. Merolla G, Santis DE, Campi F, Paladini P, Porcellini G (2010) Supraspinatus and infraspinatus weakness in overhead athletes with scapular dyskinesis: strength assessment before and after restoration of scapular musculature balance. Musculoskelet Surg 94(3): 119-125.

29. Mey DK, Danneels L, Cagnie B, Cools AM (2012) Scapular muscle rehabilitation exercises in overhead athletes with impingement symptoms: effect of a 6-week training program on muscle recruitment and functional outcome. Am J Sports Med 40(8): 1906-1915.

30. Holmgren T, Hallgren HB, Oberg B, Adolfsson L, Johansson K (2014) Effect of specific exercise strategy on need for surgery in patients with subacromial impingement syndrome: Randomised controlled study. Br J Sports Med 48(19): 1456-1457.

31. Day JM, Bush H, Nitz AJ, Uhl TL (2015) Scapular muscle performance in individuals with lateral epicondylalgia. J Orthop Sports Phys Ther 45(5): 414-424.

32. Ucurum SG, Karabay D, Ozturk BB, Kaya DO (2019) Comparison of scapular position and upper extremity muscle strength in patients with and without lateral epicondylalgia: A case-control study. J Shoulder Elbow Surg 28(6): 1111-1119.

33. Ludewig PM, Reynolds JF (2009) The association of scapular kinematics and glenohumeral joint pathologies. J Orthop Sports Phys Ther 39(2): 90-104.

34. Kibler WB, Sciascia A, Wilkes T (2012) Scapular dyskinesis and its relation to shoulder injury. J Am Acad Orthop Surg 20(6): 364-372.

35. Kibler WB, McMullen J (2003) Scapular dyskinesis and its relation to shoulder pain. J Am Acad Orthop Surg 11(2): 142-151.

36. Struyf F, Nijs J, Baeyens JP, Mottram S, Meeusen R (2011) Scapular positioning and movement in unimpaired shoulders, shoulder impingement syndrome, and glenohumeral instability. Scand J Med Sci Sports 21(3): 352-358.

37. Timmons MK, Thigpen CA, Seitz AL, Karduna AR, Arnold BL, et al. (2012) Scapular kinematics and subacromial-impingement syndrome: A metaanalysis. J Sport Rehabil 21(4): 354-370. 